\title{
ANÁLISE EXPERIMENTAL DE PILARES DE CONCRETO ARMADO, COM CARGA EXCÊNTRICA, REFORÇADOS COM CHUMBADORES E CONCRETO AUTOADENSÁVEL (CAA)
}

\section{Experimental Analysis of Reinforced Concrete Columns, under Eccentric Load, Reinforced with Anchor Bolt and Self Compacting Concrete (SCC)}

\author{
Jeovan Pereira das Virgens ${ }^{1}$, Ronaldo Barros Gomes ${ }^{2}$, Leandro Mouta Trautwein ${ }^{3}$
}

Recebido em 18 de novembro de 2013; recebido para revisão em 17 de fevereiro de 2014; aceito em 21 de fevereiro de 2014; disponível on-line em 13 de maio de 2014.

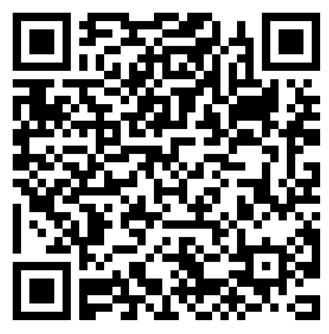

PALAVRAS CHAVE:

Pilar;

Rreforço estrutural;

Concreto autoadensável;

Parafusos Chumbadore.

* Contato com o autor:

${ }^{1}$ e-mail : jeovan2001@yahoo.com.br (J.P. Virgens )

Mestrando do Curso de Mestrado em Engenharia Civil (CMEC) Escola de Engenharia Civil (EEC) Universidade Federal de Goiás (UFG).

2e-mail : rbggomes@gmail.com (R. B. Gomes )

Professor PHD da Escola de Engenharia Civil (EEC) da Universidade Federal de Goiás (UFG).

${ }^{3}$ e-mail : leandromt@gmail.com ( L. M. Trautwein )

Professor Dr. Faculdade de Engenharia Civil, Arquitetura e Urbanismo da Universidade Estadual de Campinas - (UNICAMP)
RESUMO: O presente trabalho apresenta o estudo experimental de pilares de concreto armado reforçados com parafusos chumbadores e acréscimo de camada com $35 \mathrm{~mm}$ de concreto autoadensável na face comprimida. Foram submetidos à flexão composta reta com excentricidade inicial de $60 \mathrm{~mm}$, nove pilares com alturas iguais a $2000 \mathrm{~mm}$, assim discriminados: um Pilar de referência $\left(P_{\text {ref }}\right)$ com seção transversal de $120 \mathrm{~mm}$ x $250 \mathrm{~mm}$; um Pilar monolítico $\left(P_{\text {mon }}\right)$ com seção transversal de $155 \mathrm{~mm}$ x $250 \mathrm{~mm}$ e sete pilares, inicialmente moldados com seção transversal de $120 \mathrm{~mm} \times 250 \mathrm{~mm}$, e após, reforçados através da adição de camada de reforço de 35 $\mathrm{mm}$ e diversas configurações de posições de parafusos chumbadores na face comprimida. Exceto o Pilar de Referência, os pilares foram submetidos à excentricidade inicial de carga de $42,5 \mathrm{~mm}$, devido ao acréscimo da camada de reforço na face comprimida. Apesar de não ocorrer ruptura dos parafusos chumbadores, não foi possível evitar o desplacamento da camada de reforço. Os resultados obtidos indicam que é possível a reabilitação estrutural de pilares de concreto armado com o uso da metodologia de reforço empregada, obtendo ganho de capacidade de carga média de 358 \% em relação ao Pilar de Referência $\left(P_{\text {ref }}\right)$.

\section{INTRODUÇÃO}

Pilares são elementos lineares de eixo reto, usualmente dispostos na vertical, em que forças normais de compressão são preponderantes (ABNT NBR 6118:2007). A ruptura de um pilar pode levar uma estrutura à ruína, no todo ou em parte, o que é um fato indesejável para qualquer engenheiro estrutural. Diversas causas podem levar um pilar de concreto armado à ruptura, dentre elas: imprudência, imperícia ou negligência no seu dimensionamento; falhas na sua construção; deterioração por ataque de agentes agressivos; falta de manutenção preditiva, corretiva ou uso 
incorreto da estrutura; etc. A reabilitação estrutural de peças estruturais torna-se necessária quando ela não apresenta condições de uso. Técnicas de reforço estrutural como aumento da seção transversal com adição ou não de armadura é comumente utilizada no Brasil. Entretanto, essa técnica precisa ser mais explorada a fim de embasar os profissionais da área de estruturas a lidar com essa situação de forma segura e econômica.

Visando um melhor conhecimento do comportamento de pilares reforçados, optou-se pelo estudo experimental de pilares com adição de camada de reforço em concreto autoadensável na face comprimida e submetidos à flexo-compressão reta (Figura 1). A fim de obter maior interação entre o concreto do substrato e camada de concreto do reforço, foi aplicada a técnica de escarificação por hidrodemolidora e instalação de parafusos chumbadores variando-se o diâmetro e configuração de posicionamento dos mesmos. Em um dos pilares, foi adicionado, também, uma chapa contendo conectores de cisalhamento fixada através dos parafusos chumbadores.

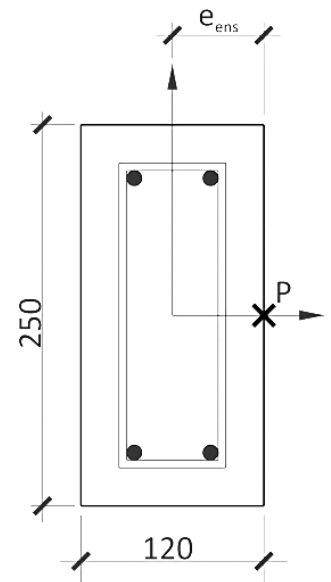

Pilar de referência $\left(P_{\text {ref }}\right)$

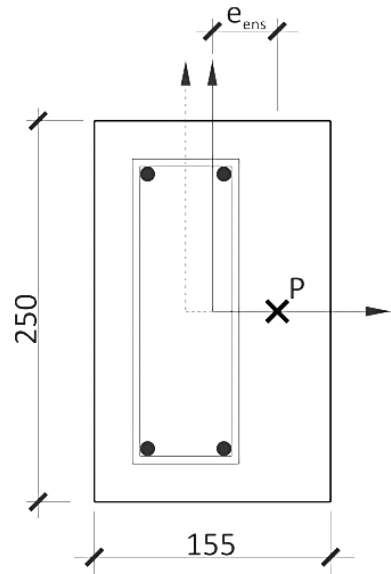

Pilar monolítico $\left(\mathrm{P}_{\operatorname{mon}}\right)$

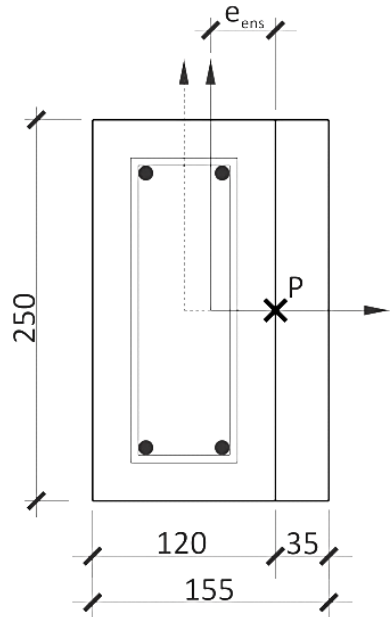

Pilar reforçado

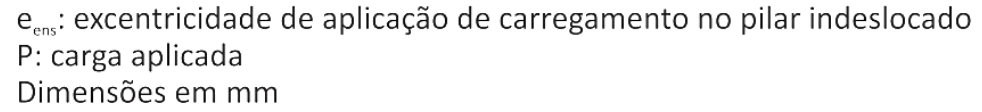

FIGURA 1: Características das seções transversais de todos os pilares.

Fonte: SAHB (2008).

\section{REVISÃO BIBLIOGRÁFICA}

Vários trabalhos foram desenvolvidos particularmente, na Universidade Federal de Goiás - UFG, com objetivo de analisar o estudo do comportamento de pilares de concreto. Dentre algumas pesquisas, podem ser citadas as de Adorno (2004), Araújo (2004), Omar (2006), Sahb (2008) e Nascimento (2009). Destas pesquisas, as de Omar (2006), Sahb (2008) e Nascimento (2009) se dedicaram à análise de comportamento de pilares com acréscimo de camada de reforço.
Adorno (2004) desenvolveu uma pesquisa avaliando o comportamento experimental de pilares de concreto simples e de concreto armado, submetidos à flexo-compressão reta. Um dos seus objetivos foi de confirmar a validação da teoria proposta por Mello (2003) que visa proporcionar uma solução analítica das equações não lineares que governam as condições de equilíbrio e de resistência da seção transversal. Adorno (2004), dentre outras conclusões, concluiu que: para todos os pilares, o relógio comparador localizado na seção média do pilar apresentou maior deslocamento; o deslocamento do consolo superior, medido pelos 
relógios, foi menor que o do consolo inferior devido à aplicação de carga ser feita na região inferior do pilar; o aumento da excentricidade inicial da força solicitante influenciou as deformações do concreto, provocando um crescimento do encurtamento do concreto.

Araújo (2004) ensaiou nove pilares em concreto sob flexo-compressão reta. $O$ seu programa experimental foi feito em três séries de ensaios: PSA, PCA4 e PCA6. A série PSA compreendeu ensaios de exemplares em concreto simples. As séries PCA4 e PCA6 envolveram o estudo de modelos em concreto armado, com armadura longitudinal composta de quatro e seis barras nervuradas retas, respectivamente, de 10 $\mathrm{mm}$ de diâmetro, cujas dimensões de seção, altura e formato são iguais aos de Adorno (2004). Foram variados em cada série de ensaio a excentricidade inicial de carga iguais a $40 \mathrm{~mm}, 50 \mathrm{~mm}$ e $60 \mathrm{~mm}$. Araújo (2004) concluiu que a influência da taxa de armadura nas deformações e nos deslocamentos, os pilares da série PCA6 apresentaram deformações inferiores nas armaduras em relação aos pilares da série PCA4, para todas as excentricidades, na face tracionada; os deslocamentos da seção central da série PCA4 foram os maiores e os pilares de concreto simples, os de menores valores, por sua ruptura frágil.

Omar (2006) enfatiza o estudo de pilares de concreto armado reforçados com concreto autoadensável (CAA) e instalação de estribos conectores nas faces de compressão e tração, isolados e simultaneamente, submetidos à flexocompressão reta. Foram submetidos a

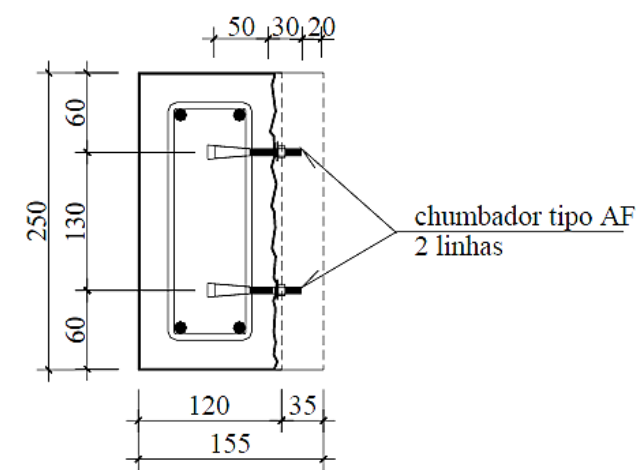

FIGURA 2: Posicionamento dos parafusos chumbadores.

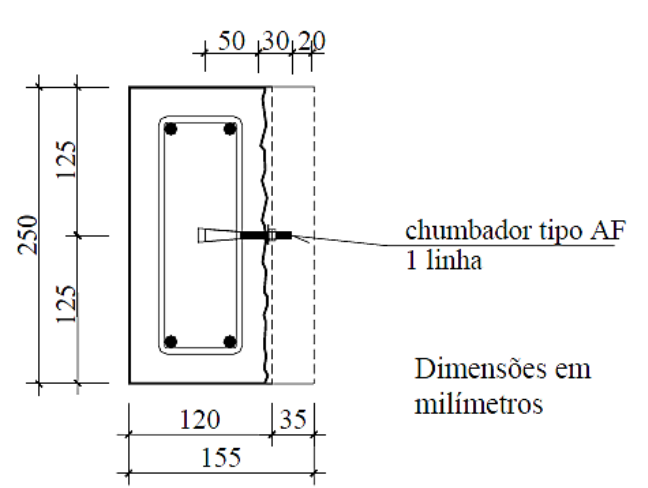

Fonte: SAHB (2008).

carregamento com excentricidade inicial de $60 \mathrm{~mm}$, oito pilares de seção transversal retangular de 120 $\mathrm{mm} \times 250 \mathrm{~mm}$, comprimento de $2000 \mathrm{~mm}$, moldados com concreto de $30 \mathrm{MPa}$ de resistência nominal à compressão aos 28 dias, com armadura longitudinal composta de quatro barras retas nervuradas de $10 \mathrm{~mm}$ de diâmetro nominal. Dois desses pilares (P1 e P2), considerados de referência, foram ensaiados até a ruptura, e os outros seis (P3 a P8) foram carregados até uma carga de parada pré-definida (próxima ao início do escoamento da armadura tracionada), sendo então reforçados e reensaiados até a ruptura. Omar (2006) concluiu que todos os pilares reforçados apresentaram carga de ruptura superior a 2,1 vezes a carga do pilar de referência. Apenas os pilares reforçados na face comprimida (PC35 e PC55) apresentaram desplacamento do concreto do reforço, indicando que a aderência do concreto do substrato com o concreto do reforço, deve ser melhorada. Uma das soluções poderia ser a substituição do fíller (pó-de-brita) pela sílica ativa, na composição do concreto autoadensável (OMAR, 2006).

Com base nos resultados de Omar (2006), Sahb (2008) propôs um estudo substituindo os estribos conectores por parafusos chumbadores com o objetivo de conter o desplacamento do concreto do reforço observado por Omar (2006). Sahb (2008) sugeriu a instalação de parafusos chumbadores posicionados na face comprimida dos pilares reforçados e acréscimo de $35 \mathrm{~mm}$ de camada de reforço em concreto autoadensável (CAA) (Figura 2). 
Os resultados da pesquisa de Sahb (2008) (Tabela 1), indicam que todos os pilares reforçados apresentaram carga de ruptura superior à carga de ruptura do pilar original de referência, confirmando o desempenho do método de reforço adotado. Em alguns pilares a ruptura foi do tipo frágil, com desplacamento da camada de reforço, entretanto a eficiência da aderência foi maior com o aumento da taxa de chumbadores. 0 pilar com a maior taxa de chumbadores rompeu com desplacamento da camada de reforço e também foi evidenciada tendência de esmagamento do concreto na região central do pilar.

\begin{tabular}{|c|c|c|c|c|c|c|c|c|c|c|c|}
\hline Pilar & $\begin{array}{c}P_{u} \\
(\mathbf{k N})\end{array}$ & $\begin{array}{l}f_{c}^{\text {sub }} \\
\text { (MPa) }\end{array}$ & $\begin{array}{l}f_{c}^{\text {ref }} \\
(\mathrm{MPa})\end{array}$ & $\begin{array}{l}E_{c}^{\text {sub }} \\
(\mathrm{GPa})\end{array}$ & $\begin{array}{c}E_{c}{ }^{\text {ref }} \\
(\mathrm{GPa})\end{array}$ & $\begin{array}{c}\rho_{\text {inic }} \\
(\%)\end{array}$ & $\begin{array}{r}\rho_{f i n} \\
(\%)\end{array}$ & $\begin{array}{l}T_{c h} \\
(\%)\end{array}$ & $\begin{array}{c}\varepsilon_{s} \text { máx } \\
(\mathrm{mm} / \mathrm{m})\end{array}$ & $\begin{array}{l}\varepsilon_{c} \text { máx } \\
(\mathrm{mm} / \mathrm{m})\end{array}$ & $\begin{array}{l}\text { Modo } \\
\text { de } \\
\text { Rup }\end{array}$ \\
\hline PA-Ref* & 139,1 & 39,1 & - & 29,6 & - & 1,05 & - & - & 2,50 & $-3,04$ & $\mathrm{EA} ; \mathrm{EC}$ \\
\hline PA-M & 397,0 & 39,1 & - & 29,5 & - & 0,81 & - & - & 2,88 & $-3,68$ & $\mathrm{EA} ; \mathrm{EC}$ \\
\hline PA-R* & 422,6 & 39,9 & 47,9 & 30,1 & 31,5 & 1,05 & 0,91 & - & 0,68 & $-2,32$ & $\mathrm{D}$ \\
\hline PA-R3 & 461,7 & 39,5 & 48,3 & 29,8 & 31,6 & 1,05 & 0,91 & 0,08 & 0,62 & $-2,16$ & $D$ \\
\hline PA-R5 & 539,6 & 39,9 & 51,8 & 30,1 & 32,9 & 1,05 & 0,91 & 0,14 & $-0,12$ & $-1,75$ & $\mathrm{D}$ \\
\hline PA-R9 & 553,4 & 39,9 & 52,0 & 30,1 & 33,0 & 1,05 & 0,91 & 0,25 & $-0,03$ & $-1,37$ & $D$ \\
\hline PB-M* & 613,0 & 51,7 & - & 35,2 & - & 0,91 & - & - & 1,41 & $-3,16$ & EC* \\
\hline PB-R5-4d* & 205,0 & 41,0 & 51,7 & 29,2 & 35,3 & 1,05 & 0,91 & 0,20 & $-0,04$ & $-0,64$ & $D$ \\
\hline PB-R9d & 225,0 & 41,1 & 52,2 & 31,0 & 35,4 & 1,05 & 0,91 & 0,25 & $-0,24$ & $-0,48$ & $\mathrm{D}$ \\
\hline PB-R9-8 & 626,3 & 41,2 & 52,5 & 31,1 & 35,4 & 1,05 & 0,91 & 0,37 & 1,25 & $-2,68$ & $\mathrm{EC}^{*} ; \mathrm{DR}$ \\
\hline
\end{tabular}

* Pilares em que a leitura das deformações foram na carga anterior à de ruptura;

$\boldsymbol{P}_{u} \quad$ : Carga de ruptura;

$\boldsymbol{f}_{c}{ }^{\text {sub }}$ : Resistência do concreto do substrato na data do ensaio;

$f_{c}{ }^{\text {ref }}$ : Resistência do concreto auto-adensável do reforço na data do ensaio;

$\boldsymbol{E}_{\boldsymbol{c}}{ }^{\text {sub }}$ : Módulo de elasticidade do concreto do substrato na data do ensaio;

$\boldsymbol{E}_{\boldsymbol{c}}{ }^{\text {ref }}$ : Módulo de elasticidade do concreto auto-adensável do reforço na data do ensaio;

$\boldsymbol{\rho}_{\text {inic }}$ : Taxa de armadura longitudinal inicial (antes do reforço);

$\rho_{\text {fin }}$ : Taxa de armadura da seção composta, após o acréscimo da camada de $35 \mathrm{~mm}$ de concreto auto-adensável e da armadura de combate à retração;

$\boldsymbol{T}_{\boldsymbol{c h}}$ : Taxa de chumbadores ( $\left.\left(\boldsymbol{A}_{\boldsymbol{c h}} / \boldsymbol{A}_{\mathbf{i n t}}\right) \boldsymbol{x} \mathbf{1 0 0}\right)$, onde $\boldsymbol{A}_{\boldsymbol{c h}}$ é a somatória das áreas das seções transversais dos chumbadores e $\boldsymbol{A}_{\mathbf{i n t}}$ a área da interface entre substrato e reforço;

$\varepsilon_{s} m a ́ x$ : Deformação máxima registrada nas barras situadas na face tracionada ou menos comprimida, na região central do pilar;

$\varepsilon_{c}$ máx : Deformação máxima registrada no concreto comprimido da região central;

$\boldsymbol{\varepsilon}_{\boldsymbol{y}}=\mathbf{2 , 9 5} \mathrm{mm} / \boldsymbol{m}$ : Deformação de início de escoamento obtida para o aço de $\boldsymbol{\phi}=\mathbf{1 0 , 0} \mathbf{m m}$;

$\boldsymbol{\varepsilon}_{\boldsymbol{u}}=\mathbf{3 , 0} \mathbf{m m} / \boldsymbol{m}$ : Deformação de esmagamento do concreto adotado pelo ACl 318M-02, para peças flexo-comprimidas;

EA: Escoamento do aço; EC: Esmagamento do concreto;

EC*: Esmagamento do concreto com indícios de escoamento do aço;

DR: Desplacamento do reforço. 


\section{PROGRAMA EXPERIMENTAL}

Os espécimes ensaiados seguiram os padrões de armadura e dimensões dos pilares já testados anteriormente na pesquisa Sahb (2008). O Programa Experimental é composto do ensaio de nove pilares moldados em concreto autoadensável (CAA) com resistência nominal característica de 30 $\mathrm{MPa}$, contendo quatro barras longitudinais de 10 $\mathrm{mm}$ de diâmetro, submetidos à flexo-compressão reta com excentricidade inicial de carregamento de $60 \mathrm{~mm}$. Os detalhes das armaduras são mostrados na Figura 3.

A preparação do reforço dos pilares foi feita seguindo as seguintes etapas: escarificação por equipamento de perfusão de água à alta pressão (hidrodemolidora) com pressão de trabalho de 320 psi, detecção da localização dos estribos (foi feito marcação prévia da localização na forma antes da concretagem), instalação dos conectores nos furos previamente feitos através de furadeira, colocação das formas do reforço, limpeza, umedecimento da superfície e concretagem. O reforço dos pilares foi executado com concreto autoadensável (CAA) com resistência nominal característica de $30 \mathrm{MPa}$, após 49 dias da concretagem do substrato. $\mathrm{Na}$ tabela 2 são apresentadas as nomenclaturas e principais características dos pilares ensaiados.

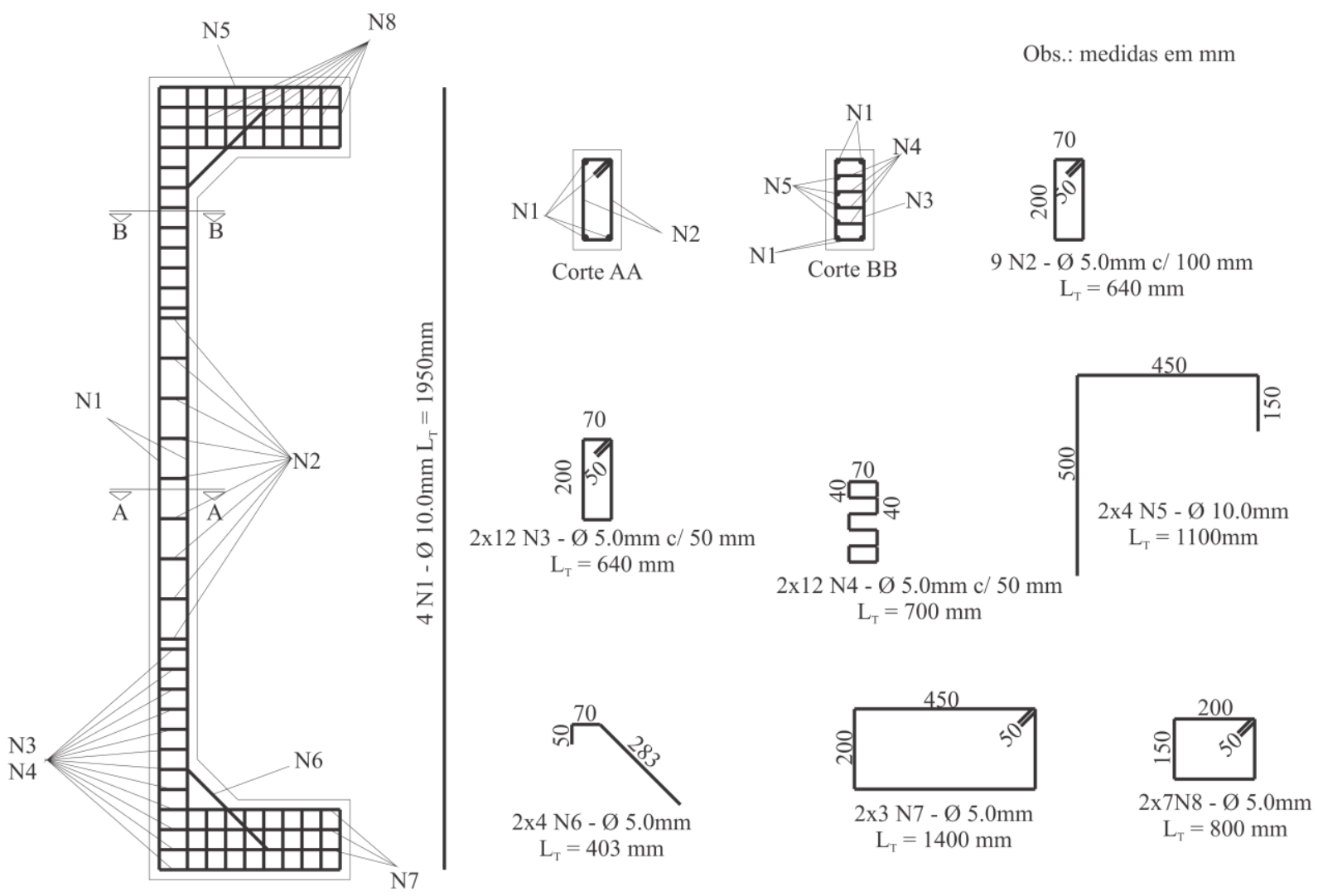

FIGURA 3: Detalhamento da armadura dos pilares. 


\section{TABELA 2: Características e nomenclatura dos pilares.}

\begin{tabular}{|c|c|c|c|c|}
\hline Nomenclaruta & Seção (mm) & $\begin{array}{l}\text { № parafusos } \\
\text { chumbadores }\end{array}$ & $\begin{array}{l}\varnothing \text { furo do parafuso } \\
\text { chumbador (mm) }\end{array}$ & $e_{\text {ens }}(\mathrm{mm})$ \\
\hline $\begin{array}{l}\text { Pilar de referência } \\
\left(P_{\text {ref }}\right)\end{array}$ & $120 \times 250$ & - & - & 60 \\
\hline $\begin{array}{l}\text { Pilar monolítico } \\
\left(\mathbf{P}_{\text {mon }}\right)\end{array}$ & $155 \times 250$ & - & - & 42,5 \\
\hline Pilar P8-150-18 & $155 \times 250$ & 18 & 8 & 42,5 \\
\hline Pilar P8-150-26 & $155 \times 250$ & 26 & 8 & 42,5 \\
\hline Pilar P6-150-18 & $155 \times 250$ & 18 & 6 & 42,5 \\
\hline Pilar P6-150-18-Ch & $155 \times 250$ & 18 & 6 & 42,5 \\
\hline Pilar P6-150-26 & $155 \times 250$ & 26 & 6 & 42,5 \\
\hline Pilar P6-150-34 & $155 \times 250$ & 34 & 6 & 42,5 \\
\hline Pilar P6-150-34-SP & $155 \times 250$ & 34 & 6 & 42,5 \\
\hline \multicolumn{5}{|c|}{$\mathbf{e}_{\text {inic }}$ : excentricidade inicial de carregamento - antes do reforço; } \\
\hline \multicolumn{5}{|c|}{$\mathbf{e}_{\text {ens }}$ : excentricidade de aplicação de carregamento na estrutura indeslocada; } \\
\hline \multicolumn{5}{|c|}{$\mathrm{E}_{\mathrm{ref}}:$ espessura da camada de reforço com concreto autoadensável (CAA); } \\
\hline \multicolumn{5}{|c|}{ Ch: Chapa metálica com pinos conectores de cisalhamento; } \\
\hline SP: parafusos chum & sem porca. & & & \\
\hline
\end{tabular}

O Pilar monolítico $\left(\mathrm{P}_{\text {mon }}\right)$, cuja seção transversal é a mesma dos pilares reforçados, porém concretado em uma única etapa foi moldado com o objetivo de analisar o comportamento deste com os pilares reforçados. Os pilares P8-150-18 e P8-150-26 foram reforçados utilizando Parafusos Chumbadores Modelo Alfa 5/16X80, diâmetro nominal de oito milímetros e comprimento efetivo igual a 80 milímetros (Figura 4). Para os outros pilares reforçados utilizou-se
Parafusos Chumbadores tipo PBA 5/16X3.1/-C/P, com diâmetro nominal de seis milímetros e comprimento efetivo de 80 milímetros (Figura 5). No Pilar P6-150-18-Ch foi fixada uma chapa metálica contendo três pinos conectores de cisalhamento (Figura 6). O pilar P6-150-34-SP é um pilar com as mesmas características do Pilar P6150-34, diferenciando-se pela ausência de porcas e arruelas. Todos os Parafusos Chumbadores são fabricados pela Âncora Sistemas de Fixação. 


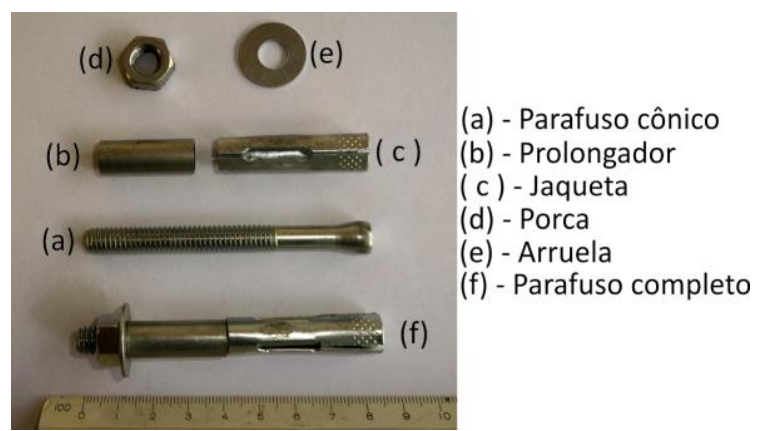

FIGURA 4: Detalhe do Parafuso chumbador $\varnothing 8 \mathrm{~mm}$.

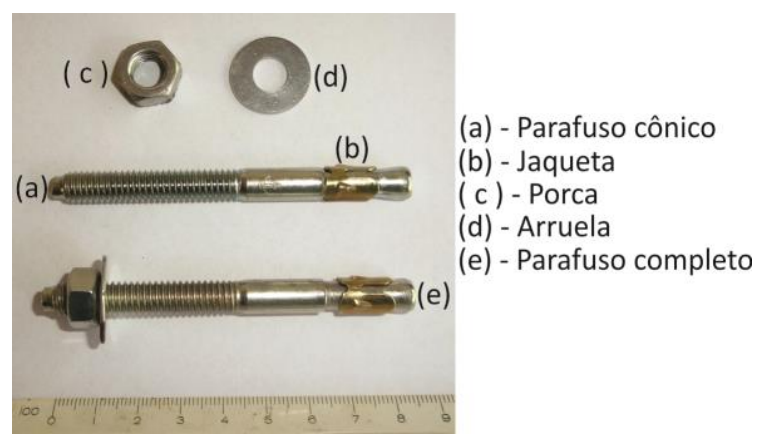

FIGURA 5: Detalhe do Parafuso chumbador $\varnothing 6 \mathrm{~mm}$.

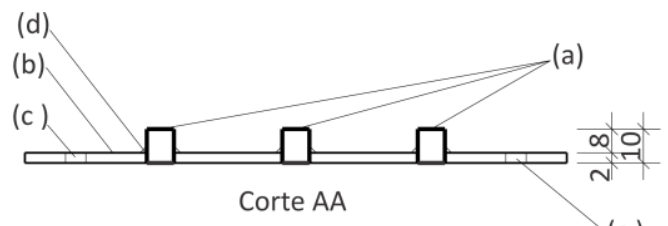

(c)

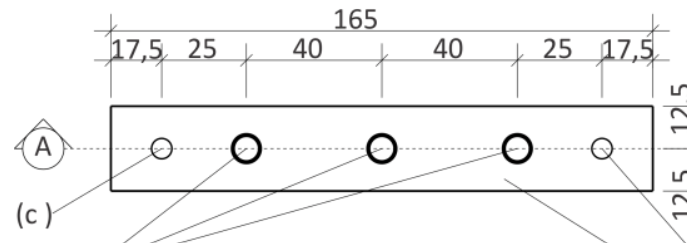

(a) Planta baixa da chapa metálica (a): chapa metálica - espessura: $2 \mathrm{~mm}$

(b): pinos conectores de cisalhamento barra CA-50 - $\emptyset=8.0 \mathrm{~mm}$

(c): furo para encaixe do parafuso chumbador $\varnothing=6.0 \mathrm{~mm}$

(d): solda elétrica

Dimensões em mm (c)

(b)

FIGURA 6: Detalhe da Chapa metálica com pinos conectores de cisalhamento.

Para medir os deslocamentos horizontais e verticais foram instalados nove relógios comparadores digitais, da marca Mitutoyo, com precisão de 0,01 $\mathrm{mm}$, denominados $\mathrm{R} 1$ à $\mathrm{R} 9$ (Figuras 8). Os relógios comparadores foram fixados com auxílio de uma base magnética acoplada em um suporte vertical, sendo o cursor posicionado em chapas metálicas coladas no pilar na posição de projeto.

Os relógios comparadores foram removidos antes da ruptura dos pilares para não serem danificados; após a retirada dos relógios comparadores a leitura dos deslocamentos na posição do relógio R3, continuou sendo efetuada pelo monitoramento, à olho nu, através do deslocamento de uma régua, com escala milimétrica, devidamente fixada ao pilar. Para medir a deformação na armadura, foram colados dois extensômetros de resistência elétrica (strain gauges), tipo PA-06-250BA-120L, em cada barra longitudinal (Figura 12). Para aferição da deformação no concreto, foram instalados quatro extensômetros, tipo PA-06-201BA-120L, na face mais comprimida dos pilares (Figura 12). Tanto os extensômetros instalados nas armaduras como os instalados no concreto, foram fabricados pela Excel Sensores e posicionados na altura media do pilar. Para leitura das deformações de todos os extensômetros foi utilizado o equipamento de coleta de dados AGILENT BenchLink Data Logger Modelo 34970A.

O detalhamento da posição e espaçamentos dos parafusos chumbadores de todos os pilares ensaiados são mostrados na Figura 7. Os ensaios foram realizados em um pórtico fixado numa laje de reação conforme Figura 8. 


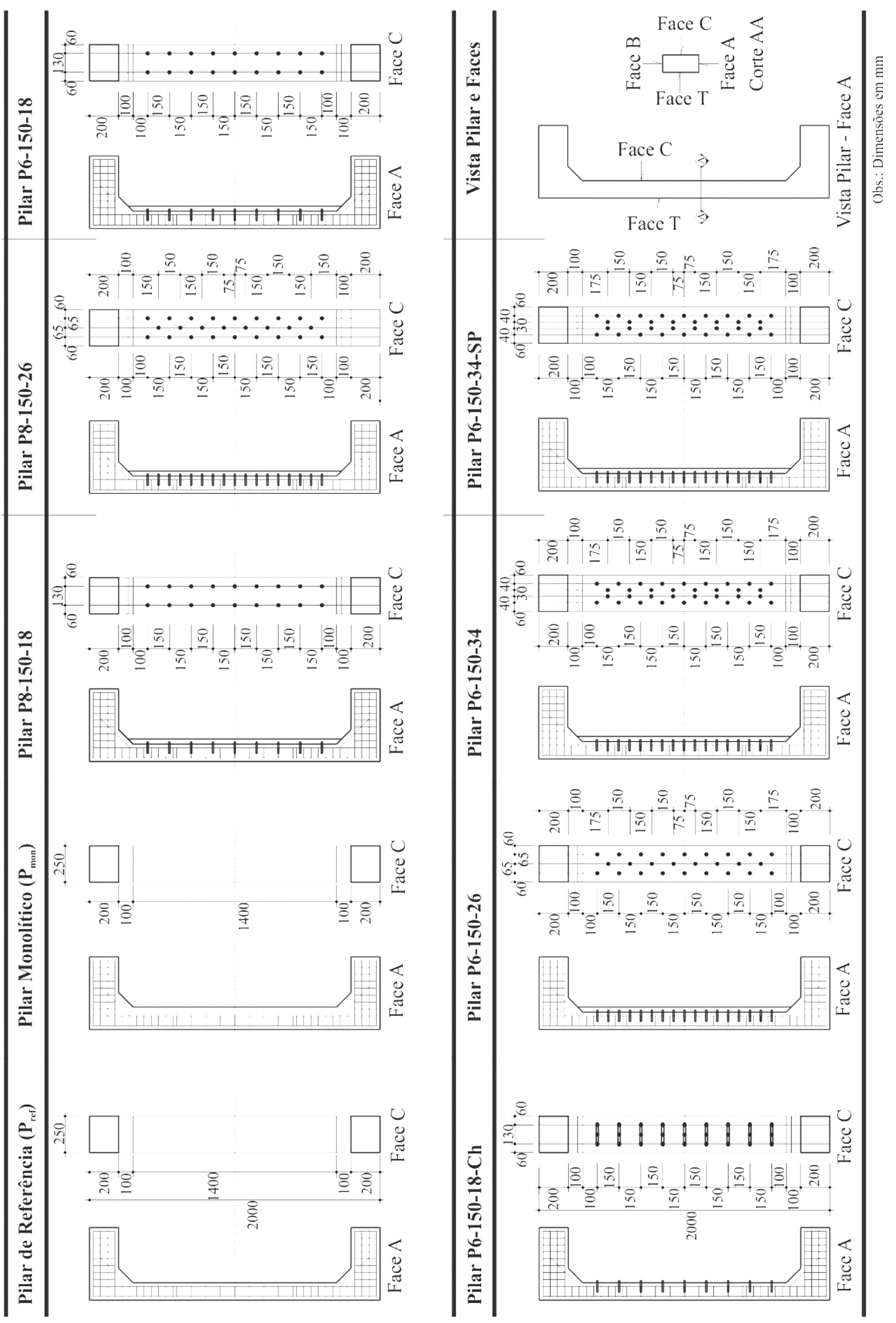

FIGURA 7: Detalhamento da posição e espaçamento dos parafusos chumbadores. 

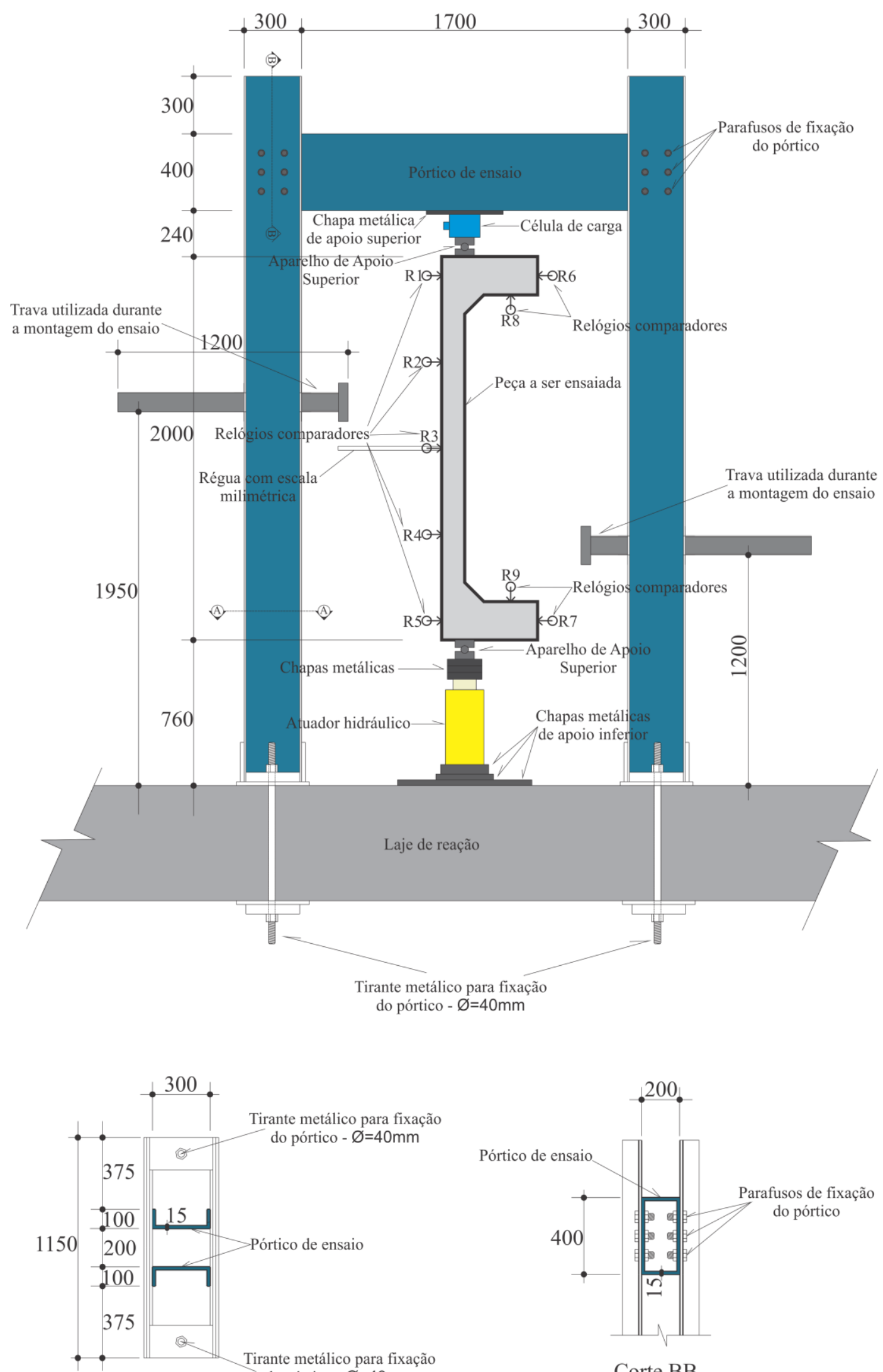

Corte AA do pórtico $-\varnothing=40 \mathrm{~mm}$

Corte BB

FIGURA 8: Detalhamento do pórtico de realização dos ensaios. 


\section{RESULTADOS E DISCUSSÕES}

\subsection{CARGA E MODO DE RUPTURA}

Todos os pilares reforçados apresentaram cargas de ruptura maiores que o Pilar de referência $\left(P_{\text {ref }}\right)$ e próximas, porém abaixo, da carga de ruptura do Pilar monolítico $\left(P_{\text {mon }}\right)$. A influência do número de parafusos chumbadores utilizados nos pilares reforçados alterou o comportamento dos deslocamentos destes pilares: foi observado que quanto maior o número de chumbadores, menor o deslocamento do relógio comparador R3, possibilitando maior carga última de ruptura $\mathrm{P}_{\mathrm{u}}$.

Os pilares reforçados apresentaram ganho de resistência de carga entre 2,68 e 4,19 vezes a carga de ruptura do pilar de referência $\left(P_{\text {ref }}\right)$; no entanto nenhum deles superou a carga de ruptura do Pilar monolítico $\left(P_{\text {mon }}\right)$. Todos os pilares reforçados tiveram rompimento brusco com desplacamento da camada de reforço, apesar de alguns apresentarem processo de escoamento da armadura na região tracionada. A diferença da resistência de compressão entre os concretos do substrato e reforço foi de no máximo 2,4 MPa. Com relação à quantidade de parafusos chumbadores, a carga de ruptura aumentou com o aumento do número de chumbadores, contudo não evitou o desplacamento do reforço. Na Figura 9 são apresentados os aspectos visuais da ruptura de alguns pilares ensaiados.

Na Tabela 3, são apresentados as cargas e modo de ruptura de todos os pilares ensaiados.

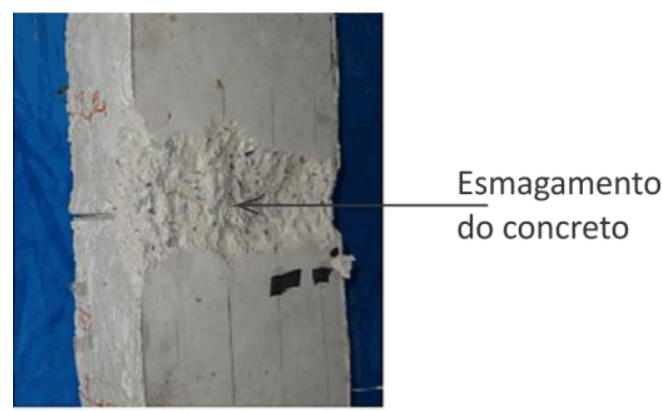

Pilar de Referência $\left(\mathrm{P}_{\text {ref }}\right)$

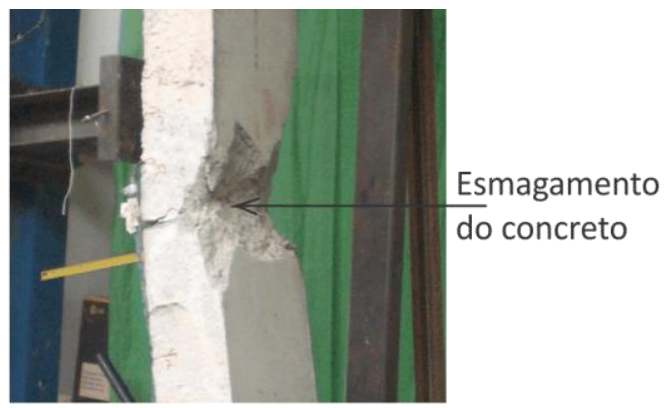

Pilar Monolítico $\left(\mathrm{P}_{\text {mon }}\right)$

Pilar P6-150-34-SP

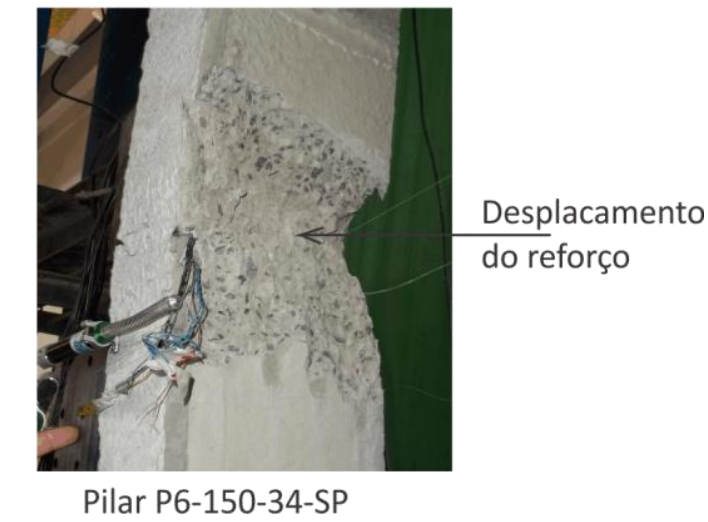

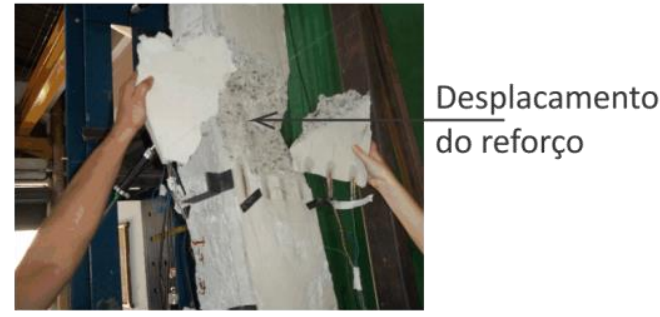

Pilar P6-150-34
FIGURA 9: Aspecto visual da ruptura do Pilar de referência $\left(P_{\text {ref }}\right)$, Pilar monolítico $\left(P_{\text {mon }}\right)$, Pilar P6-150-34 e Pilar P6-150-SP. 
TABELA 3: Cargas e modo de ruptura dos pilares ensaiados.

\begin{tabular}{|c|c|c|c|c|c|c|c|c|c|}
\hline Pilar & $\begin{array}{c}\mathrm{P}_{\mathrm{u}} \\
(\mathrm{kN})\end{array}$ & $\frac{\mathrm{P}_{\mathrm{u}}}{\mathrm{P}_{\mathrm{u}} \text { ref }}$ & $\frac{\mathrm{P}_{\mathrm{u}}}{\mathrm{P}_{\mathrm{u}} \mathrm{mon}}$ & $\begin{array}{c}\mathrm{f}_{\mathrm{sub}}^{\mathrm{c}} \\
(\mathrm{MPa})\end{array}$ & $\begin{array}{c}\mathrm{f}_{\mathrm{ref}}^{\mathrm{c}} \\
(\mathrm{MPa})\end{array}$ & $\begin{array}{c}\mathrm{P}_{\mathrm{u}}^{\text {leitura }} \\
(\mathrm{kN})\end{array}$ & $\frac{\varepsilon_{\mathrm{s}, \text { máx }}}{\varepsilon_{\mathrm{y}}}$ & $\frac{\varepsilon_{\mathrm{c}, \text { máx }}}{\varepsilon_{\mathrm{u}}}$ & $\begin{array}{l}\text { Modo de } \\
\text { rup }\end{array}$ \\
\hline Pilar de referência $\left(P_{\text {ref }}\right)$ & 126,7 & 1 & 0,23 & 41,9 & - & 120,0 & $>1$ & 0,82 & EA-EC \\
\hline Pilar monolítico $\left(\mathbf{P}_{\text {mon }}\right)$ & 542,2 & 4,28 & 1 & 41,3 & - & 540,0 & 0,56 & 0,60 & EA-EC \\
\hline Pilar P8-150-18 & 453,2 & 2,68 & 0,84 & 41,4 & 39,7 & 450,0 & $>1$ & 0,77 & $\mathrm{DR}$ \\
\hline Pilar P8-150-26 & 442,5 & 3,49 & 0,82 & 41,5 & 40,1 & 440,0 & 0,81 & 0,97 & $\mathrm{DR}$ \\
\hline Pilar P6-150-18 & 390,8 & 3,08 & 0,72 & 42,8 & 44,0 & 390,0 & $>1$ & 0,91 & $\mathrm{DR}$ \\
\hline Pilar P6-150-18-Ch & 427,2 & 3,37 & 0,79 & 43,8 & 46,2 & 420,0 & 0,43 & 0,71 & $\mathrm{DR}$ \\
\hline Pilar P6-150-26 & 517,1 & 4,08 & 0,95 & 43,0 & 44,4 & 510,0 & 0,90 & $>1$ & $\mathrm{DR}$ \\
\hline Pilar P6-150-34 & 528,3 & 4,17 & 0,97 & 43,2 & 44,6 & 520,0 & 0,65 & 0,90 & DR \\
\hline Pilar P6-150-34-SP & 531,0 & 4,19 & 0,98 & 43,6 & 45,9 & 530,0 & $>1$ & 0,99 & $\mathrm{DR}$ \\
\hline $\begin{array}{l}\mathbf{P}_{\mathrm{u}} \text { : carga última de ruptu } \\
\mathbf{P}_{\mathrm{u}}^{\text {leitura }} \text { : carga da última l } \\
\mathbf{f}_{\mathrm{c}}^{\text {sub }} \text { : resistência à compr } \\
\mathbf{f}_{\mathrm{c}}^{\text {ref }} \text { : resistência à compre }\end{array}$ & $\begin{array}{l}\text { a; } \\
\text { tura do } \\
\text { ssão do } \\
\text { são do c }\end{array}$ & $\begin{array}{l}\text { quipam } \\
\text { oncretc } \\
\text { ncreto }\end{array}$ & $\begin{array}{l}\text { nto de co } \\
\text { lo substra } \\
\text { o reforço }\end{array}$ & $\begin{array}{l}\text { ta de dac } \\
\text { (CAA); } \\
\text { AA); }\end{array}$ & & & & & \\
\hline \multicolumn{10}{|c|}{$\boldsymbol{\varepsilon}_{\mathrm{y}}:$ deformação de início de escoamento obtida para o aço; } \\
\hline \multicolumn{10}{|c|}{$\varepsilon_{\mathrm{u}}$ : deformação de esmagamento do concreto segundo ABNT NBR 6118:2007; } \\
\hline \multicolumn{10}{|c|}{$\varepsilon_{c}:$ deformação do concreto; } \\
\hline \multicolumn{10}{|l|}{ EA: escoamento do aço; } \\
\hline \multicolumn{10}{|c|}{ EC: esmagamento do concreto; } \\
\hline DR: desplacamento do $r$ & orço. & & & & & & & & \\
\hline
\end{tabular}

\subsection{DESLOCAMENTOS}

Os deslocamentos horizontais e verticais do Pilar de referência $\left(P_{\text {ref }}\right)$, Pilar monolítico $\left(P_{\text {mon }}\right)$, Pilar P6-150-34 e Pilar P6-150-34-SP são mostrados nas Figuras 10 a 13; estes dois pilares reforçados foram evidenciados porque foram os que obtiveram cargas de rupturas mais próximas do Pilar monolítico $\left(P_{\text {mon }}\right)$, tendo os restantes apresentado carga de ruptura situadas entre a carga de ruptura do Pilar de referência $\left(P_{\text {ref }}\right)$ e do Pilar monolítico $\left(P_{\text {mon }}\right)$. Na Figura 14 são apresentados os deslocamentos dos relógios R3 de todos os pilares ensaiados. O relógio comparador R3 e a régua, com escala milimétrica, situados na altura média do pilar, foram os que apresentaram os maiores deslocamentos em todos os pilares. $\mathrm{O}$ critério utilizado para a retirada dos relógios comparadores foi o monitoramento da deformação do concreto na face mais comprimida, quando próximo de $3,5 \mathrm{~mm} / \mathrm{m}$, e registrada pela leitura da carga denominada $P_{u, l e i t u r a}$ enquanto que a carga última de ruptura é dada por $\mathrm{P}_{\mathrm{u}}$. Os relógios comparadores R2 e R4, apesar de serem posicionados em seções simétricas do pilar, não apresentaram deslocamentos iguais: a razão disto é que a carga sendo aplicada pelo macaco hidráulico posicionado na parte inferior do pilar, faz com que o deslocamento do relógio R4, mais próximo do apoio inferior, é mais afetado pelo fluxo de carga ao longo do pilar, se deslocando sensivelmente mais que relógio $\mathrm{R} 2$. 


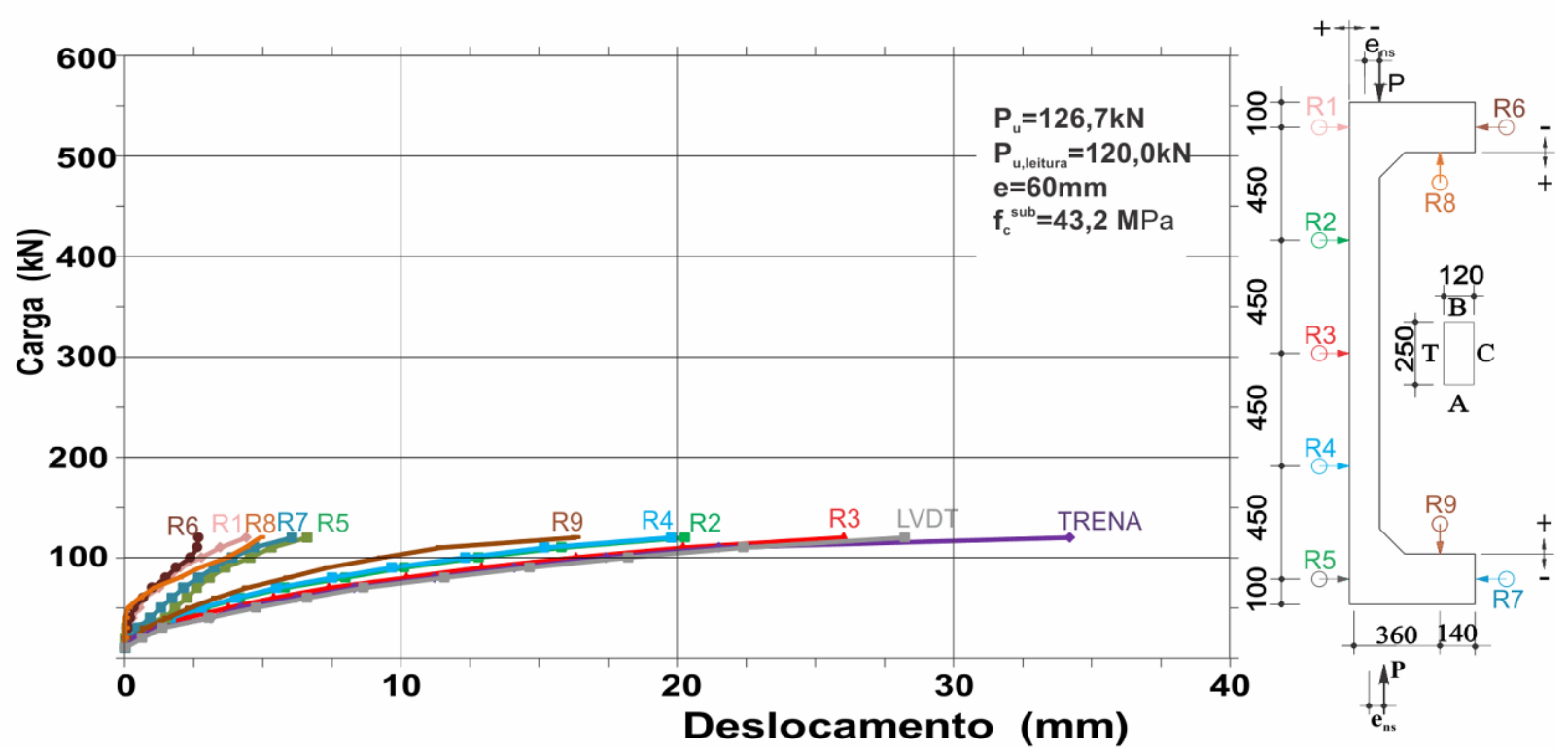

FIGURA 10: Carga x Deslocamento - Pilar de referência $\left(P_{\text {ref }}\right)$.

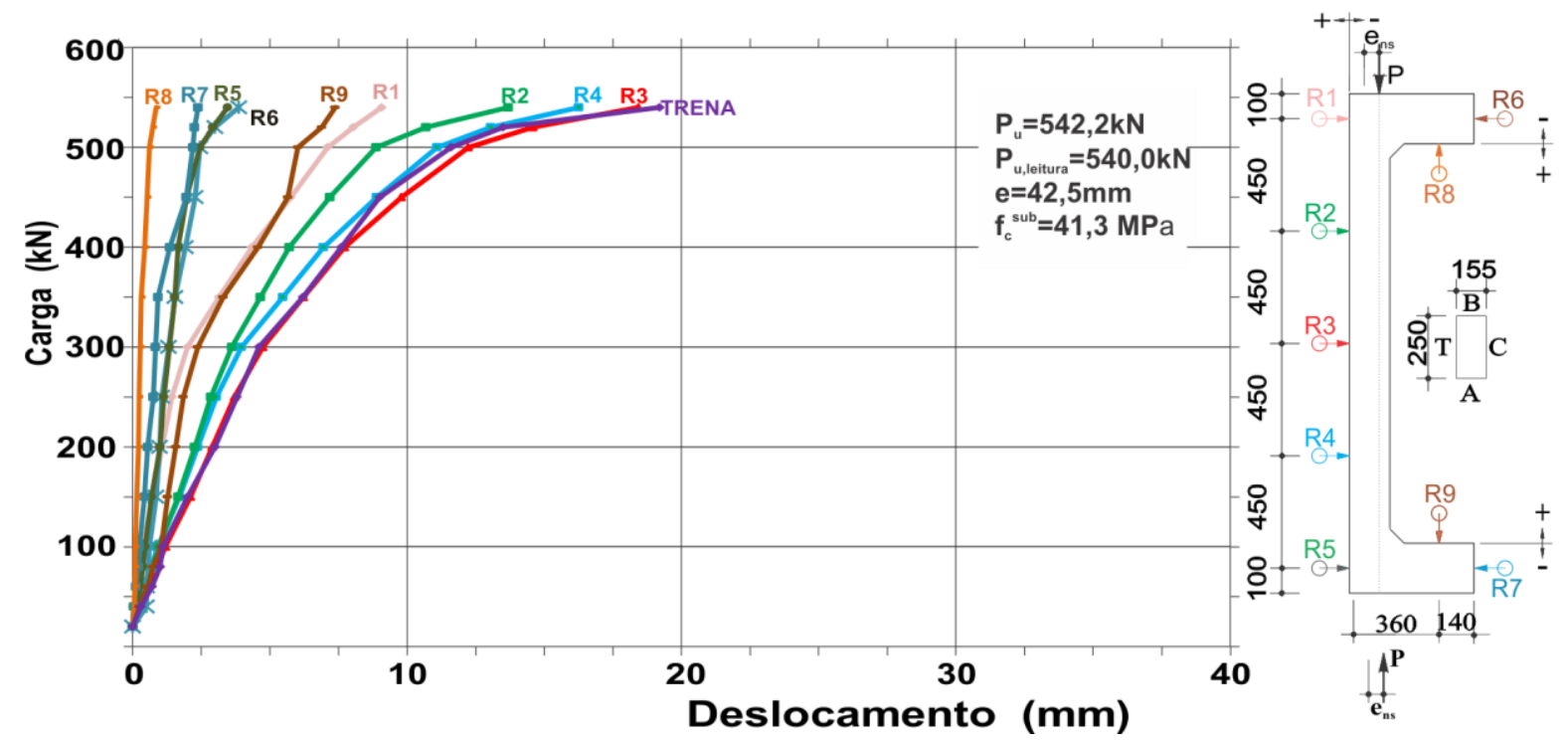

FIGURA 11: Diagrama Carga $x$ Deslocamento - Pilar monolítico $\left(P_{\text {mon }}\right)$. 


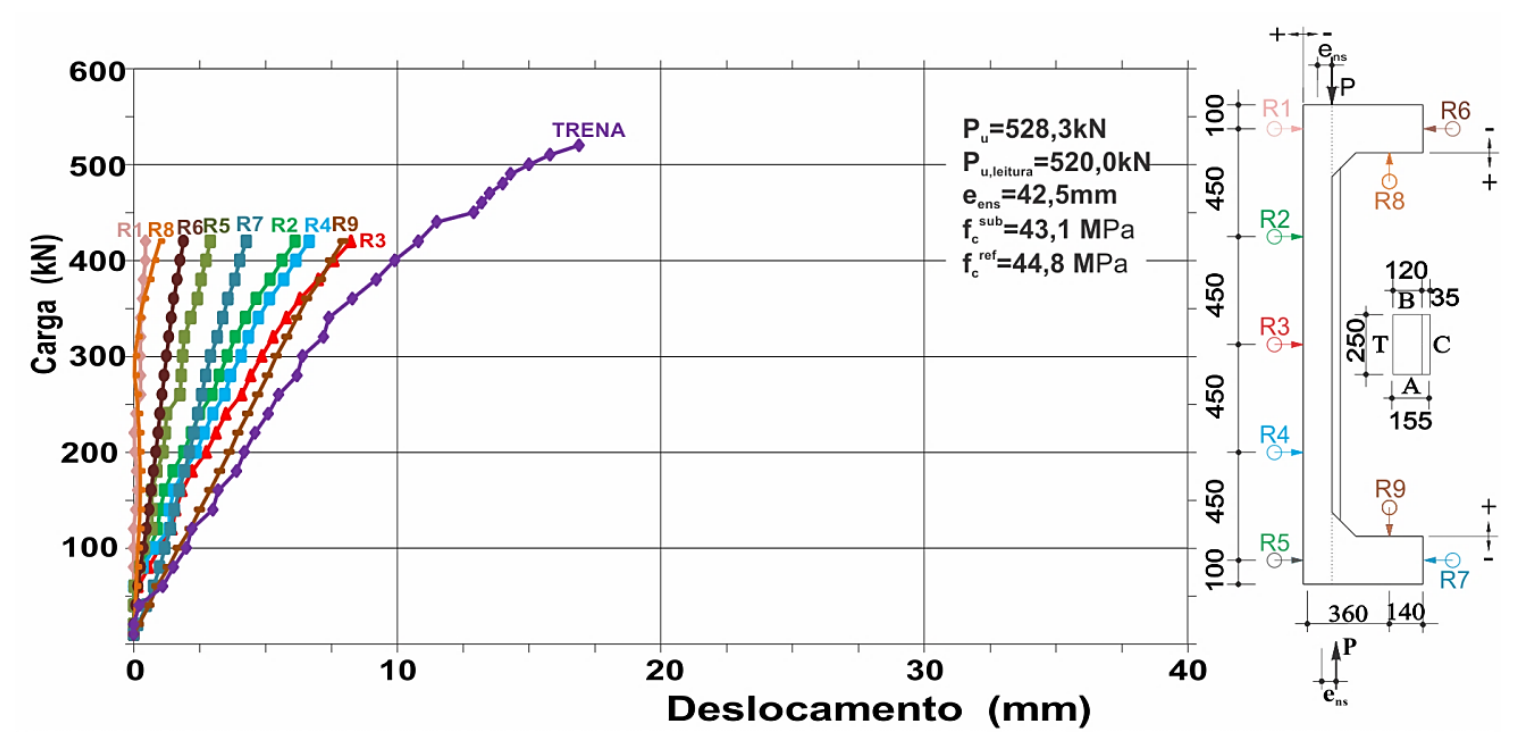

FIGURA 12: Diagrama Carga x Deslocamento - Pilar P6-150-34.

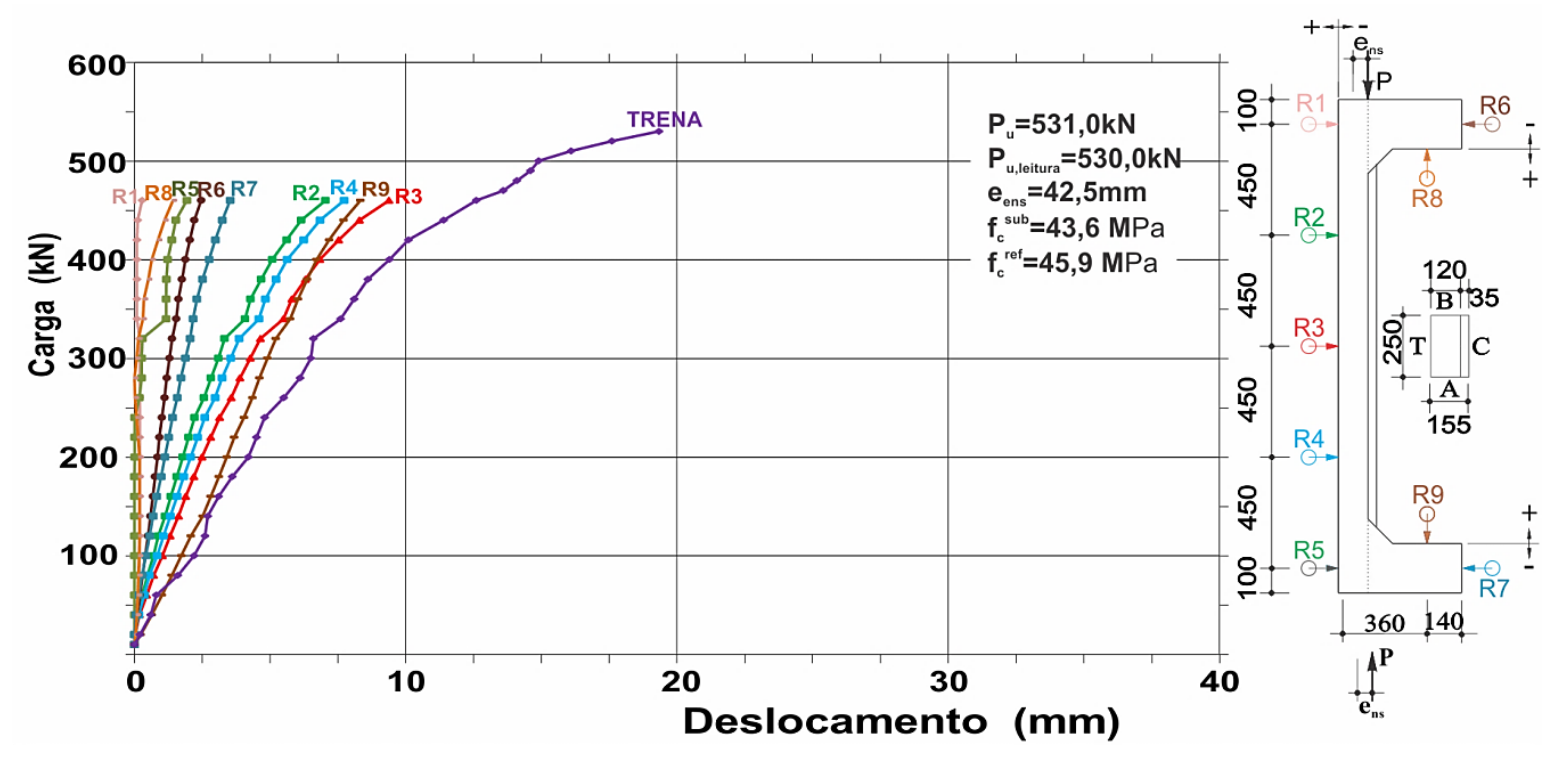

FIGURA 13: Diagrama Carga x Deslocamento Pilar P6-150-34-SP. 


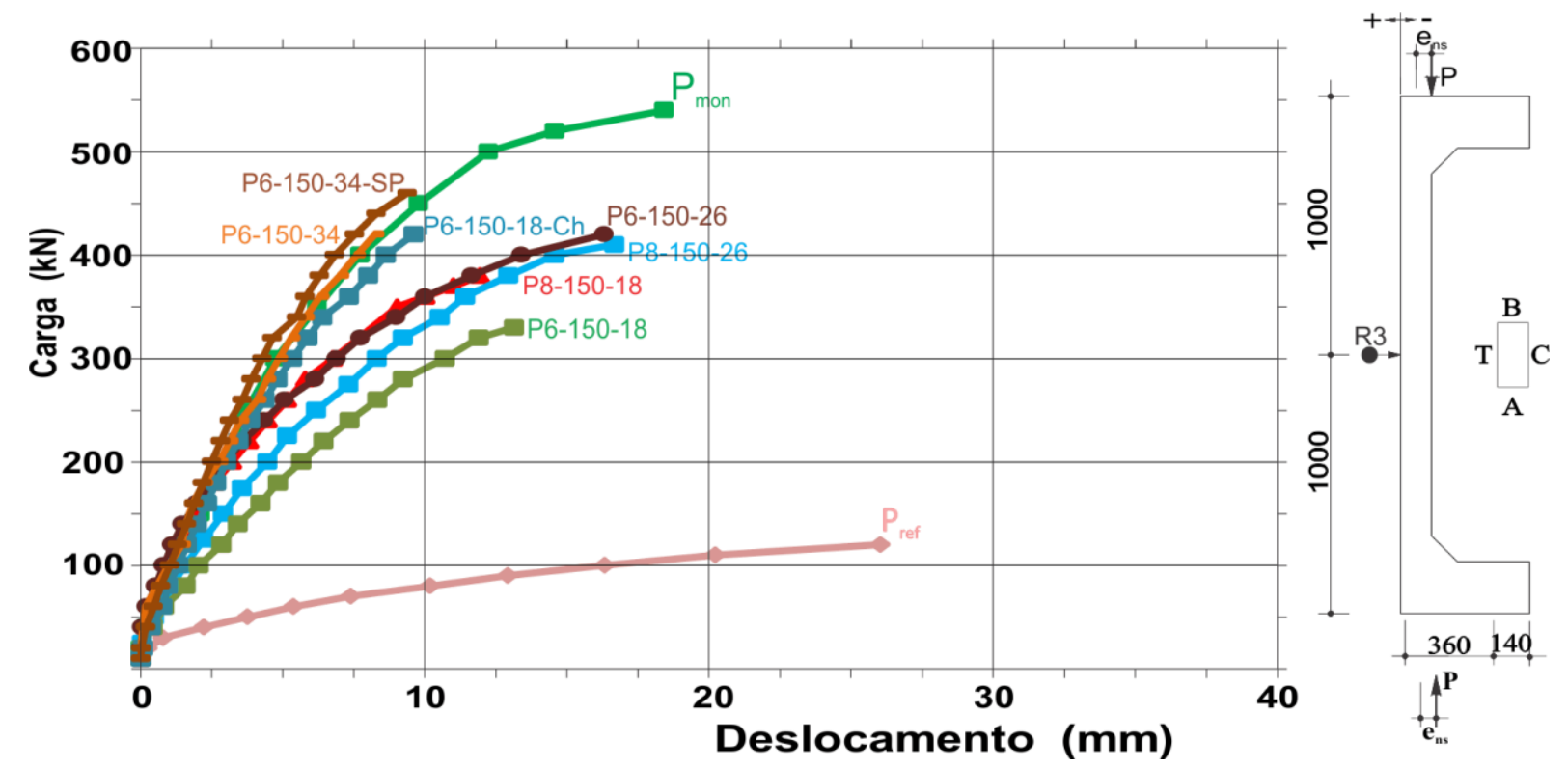

FIGURA 14: Diagrama Carga x Deslocamento dos Relógios Comparadores R3 de todos os Pilares.

\subsection{DEFORMAÇÕES DA ARMADURA}

A Figura 15 apresenta as deformações máximas nas armaduras situadas na face mais tracionada (Face T). As barras da armadura longitudinal de diâmetro de $10 \mathrm{~mm}$, foram devidamente caracterizadas obtendo-se deformação de início de escoamento $\left(\varepsilon_{y}\right)$ igual à $2,78 \%$.

Pode-se observar que os pilares $P_{\text {ref, }}$
P6-150-18, P8-150-18 e P6-150-34-SP, apresentaram nitidamente que a armadura na região tracionada estava em processo de escoamento na carga anterior à carga de ruptura. Os pilares P6-150-26, P8-150-26 e P6-150-34-SP apesar de não apresentarem o escoamento da armadura, pode-se notar uma tendência de escoamento: suas curvas de deformações tendem a tomar uma horizontalidade em direção à deformação de escoamento.

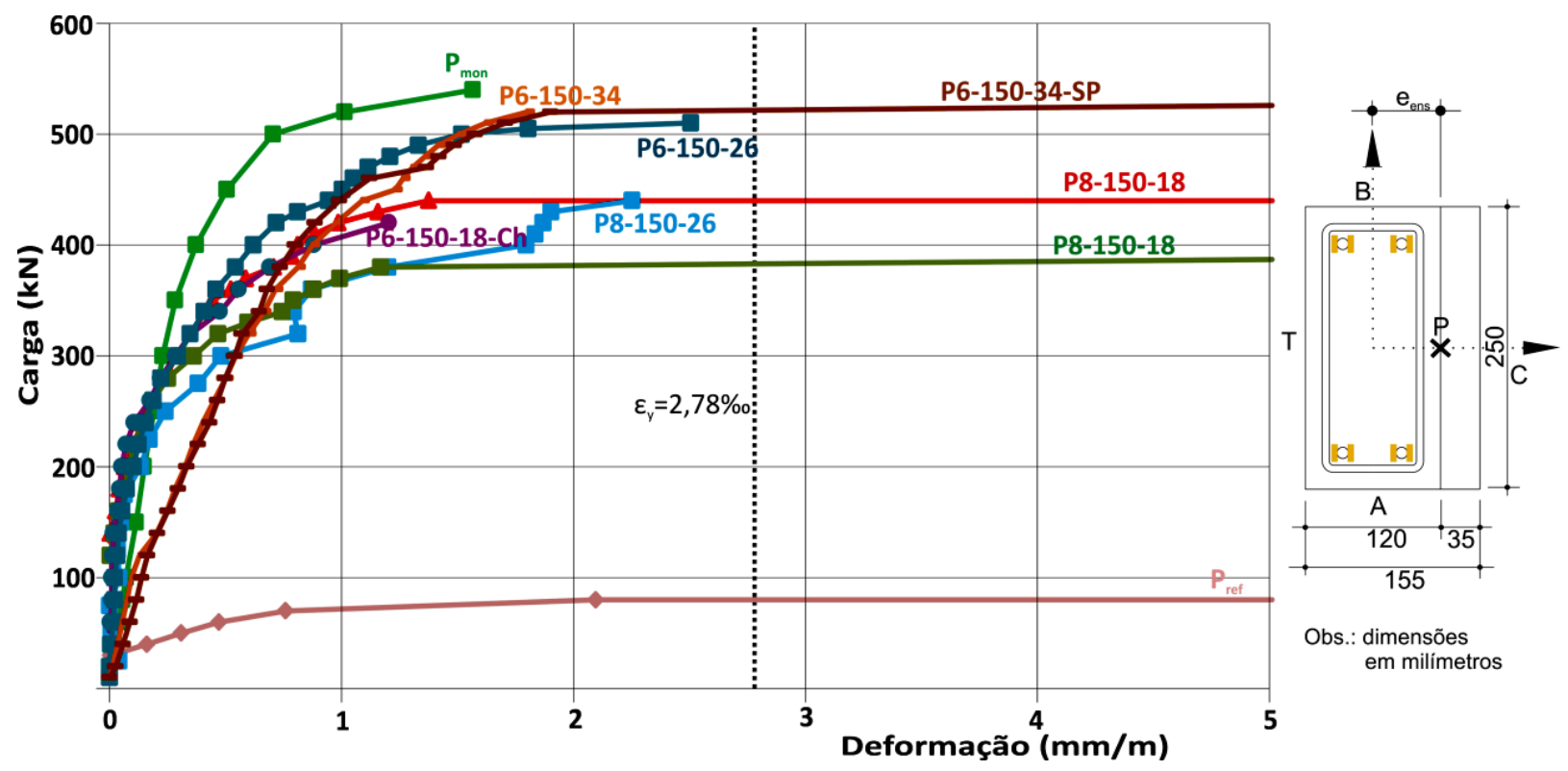

FIGURA 15: Diagrama Carga x Deformação Máxima da Armadura na Região Tracionada de todos os Pilares. 


\subsection{DEFORMAÇÕES DE COMPRESSÃO DO CONCRETO}

Quanto à deformação de esmagamento do concreto, foi adotada o que preconiza a ABNT NBR 6118:2007. Na figura 16 são mostradas as deformações máximas do concreto na face mais comprimida de todos os pilares. O pilar de referência foi o que obteve maior deformação de compressão para o mesmo estágio de carregamento, chegando a uma deformação máxima de 2,87 $\mathrm{mm} / \mathrm{m}$, evidenciando uma tendência de esmagamento do concreto, tendo em vista que essa leitura foi feita no carregamento anterior à carga de ruptura $\mathrm{P}_{\mathrm{u}}$. Todos os pilares reforçados, exceto os pilares P8-150-18 e P6-15018-Ch, apresentaram deformações de compressão do concreto próximas da deformação última de esmagamento. Os pilares P8-150-18 e P6-150-18-Ch apresentaram rompimento prematuro, apresentando deformação de $2,70 \mathrm{~mm} / \mathrm{m}$ e 2,49 $\mathrm{mm} / \mathrm{m}$, respectivamente.

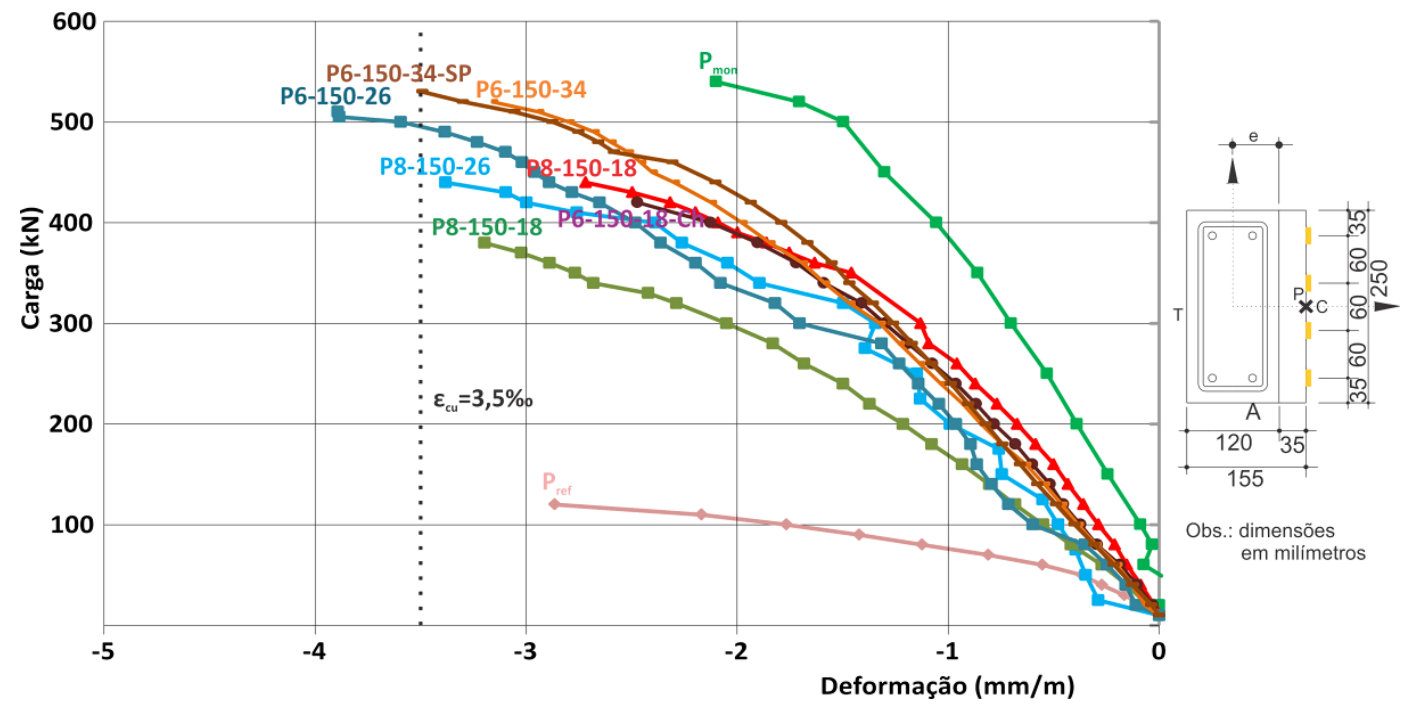

FIGURA 16: Diagrama Carga x Deformação Máxima de Compressão do concreto na face mais comprimida de todos os pilares.

\section{CONCLUSÕES}

Os pilares reforçados apresentaram carga de ruptura superior à carga de ruptura do Pilar de referência $\left(P_{\text {ref }}\right)$, sugerindo que a técnica de reforço adotada é satisfatória.

$O$ aumento da quantidade de Parafusos chumbadores possibilitou o ganho de resistência de carga dos pilares reforçados, contudo não impediu o desplacamento do reforço, apesar de que alguns pilares (P6-150-34 e P6-150-34-SP) apresentarem tendência de escoamento do aço e esmagamento do concreto.

Os deslocamentos na altura média dos pilares reforçados sofreram uma redução com o aumento da quantidade de parafusos chumbadores, sugerindo um ganho de rigidez do pilar.
Todos os pilares reforçados tiveram rompimento brusco da camada de concreto do reforço.

Em nenhum dos casos estudados houve ruptura dos parafusos chumbadores utilizados, podendo-se concluir que apresentaram um bom desempenho.

\section{AGRADECIMENTOS}

Ao CNPq e PROCAD, pelo financiamento da pesquisa, à empresa Realmix pelo fornecimento do concreto autoadensável (CAA), à Carlos Campos Construções e Consultoria Ltda pela disponibilização do equipamento e mão-de-obra para operação da hidrodemolidora, à PUC-GO pelos ensaios de tração das barras de aço. 


\section{REFERÊNCIAS BIBLIOGRÁFICAS}

ABNT: Associação Brasileira de Normas Técnicas. NBR 6118:2007 - Projeto de estruturas de concreto Procedimento. Rio de Janeiro, 2007.

ADORNO, A. L. C. Análise Teórica e Experimental de Pilares em Concreto Simples e Armado sob FlexoCompressão Reta. Tese de Doutorado. Departamento de Engenharia Civil e Ambiental, UnB, Brasília, DF, 399p, 2004.

ARAÚJO, L. M. B. Análise Teórica e Experimental de Pilares de Concreto Submetidos à Flexão Normal Composta. Dissertação de Mestrado - CMEC/EEC/UFG, Goiânia-GO, 196p, 2004.

MELLO, E. L. Concreto Armado: Resistência Limite à Flexão Composta Normal e Oblíqua. 1a. ed., Brasília: Editora Universidade de Brasília: FINATEC, 224 p. 2003.

NASCIMENTO, P. P. Experimental analysis of reinforced concrete columns strengthened with self-compacting concrete and connectors. Ibracon Structures and Materials Journal, v. 5, n. 3, p. 305-315, jun. 2012.

OMAR, M. Y. M. Experimental Analysis of Reinforced Concrete Columns Strengthened with Self-Compacting Concrete. Ibracon Structures and Materials Journal, v. 3, n. 3, p. 271-283, set. 2010.

OMAR, M. Y. M. Análise Experimental de Pilares de Concreto Armado Reforçados com Concreto AutoAdensável (CAA). Dissertação (Mestrado), CMEC/EEC/UFG, Goiânia, Goiás. 266 p. 2006.

SAHB, K. F. P. Análise Experimental de Pilares de Concreto Armado Submetidos à Flexo-Compressão, Reforçados com Concreto Auto-Adensável e Chumbadores. 224f. Dissertação (Mestrado) cmec/eec/UFG, Goiânia, Goiás. 224 p. 2008. 